ANALISIS PENDAPATAN USAHATANI UBI JALAR (Ipomea batatas L.) DI DESA PANTI KECAMATAN PANTI KABUPATEN JEMBER

\title{
ANALYSIS OF FARMING INCOME OF SWEET POTATO (Ipomea batatas L.) IN VILLAGE OF PANTI, SUB-DISTRICT PANTI, DISTRICT OF JEMBER
}

\author{
M. Sandi El Yasin ${ }^{1}$, Endang Wahyu Pudjiastutik ${ }^{2}$ \\ ${ }^{1}$ Program Studi Agribisnis Universitas Islam Jember, Indonesia \\ ${ }^{2}$ Dosen pada Program Studi Agribisnis Universitas Islam Jember, Indonesia \\ email: endangwp9@gmail.com.(082234365006)
}

Diterima: 08 Agustus 2019 Disetujui: 03 September 2019

\begin{abstract}
ABSTRAK
Pemenuhan kebutuhan pangan mayoritas penduduk Indonesia masih sangat tergantung pada beras. Hal ini menimbulkan permasalahan bagi bangsa Indonesia karena jumlah ketersediaan beras nasional tidak mampu menutupi kebutuhan pangan penduduk yang semakin meningkat, sehingga dibutuhkan alternatif komoditas substitunya seperti Ubi Jalar. Petani ubi jalar di Desa Panti Kecamatan Panti Kabupaten Jember memiliki produktivitas yang sulit ditingkatkan dengan harga yang rendah. Tujuan penelitian ini adalah 1) Untuk mengetahui tingkat Pendapatan usahatani ubi jalar, dan 2) Untuk mengetahui tingkat efisiensi Penggunaan biaya usahataninya. Hasil penelitian menunjukkan bahwa ratarata total biaya usahatani ubi jalar per hektar sebanyak Rp 22.052.029,49 dengan rata-rata total penerimaan usahatani sebanyak Rp. 63.444.198,78, sehingga pendapatan usahataninya mencapai $\mathrm{Rp}$ 41.392.169,29. Selanjutnya kegiatan usahatani ubi jalar di lokasi penelitian sudah efisien yang ditandai dengan nilai $\mathrm{R} / \mathrm{C}$ sebesar 2,15.
\end{abstract}

Kata kunci: Usahatani Ubi Jalar, Pendapatan, dan efisiensi

\begin{abstract}
Meeting the food needs of the majority of Indonesia's population is still very dependent on rice. This raises problems for the Indonesian people because the amount of national rice availability is unable to cover the food needs of the population which is increasing, so that alternative substitute commodities such as Sweet Potatoes are needed. Sweet potato farmers in Village of Panti, Sub-District of Panti, District of Jember have productivity that is difficult to increase with low prices. The purpose of this study is 1) To find out the level of income of sweet potato farming, and 2) To determine the level of efficiency of the use of farming costs. The results showed that the average total cost of sweet potato farming per hectare was IDR 22,052,029.49 with an average total farm income of IDR 63,444,198.78, so that the farm income reached IDR 41,392,169.29. Furthermore, the activity of sweet potato farming in the study location was efficient, which was marked by an $R / C$ value of 2.15 .
\end{abstract}

Keywords: Sweet Potato Farming, Revenue, and Efficiency

\section{PENDAHULUAN}

Pangan merupakan kebutuhan manusia yang paling mendasar karena berpengaruh terhadap eksistensi dan ketahanan hidup manusia itu sendiri. Pembangunan ketahanan pangan di Indonesia telah ditegaskan dalam Undang-Undang Nomor 7 tahun 1996 tentang Pangan yang dirumuskan sebagai usaha mewujudkan ketersediaan pangan bagi seluruh rumah tangga dalam jumlah yang cukup, mutu dan gizi yang layak, aman dikonsumsi, merata serta terjangkau oleh setiap individu. Oleh karena itu, ketahanan pangan menjadi salah satu isu paling strategis dalam konteks pembangunan nasional, khususnya bagi negara berkembang seperti Indonesia (Mariyam, Yuliati, dan Hidayati, 2009).

Salah satu jenis tanaman pangan yang sudah lama di kenal dan di budidayakan oleh petani di seluruh wilayah nusantara adalah tanaman Ubi jalar. Potensi nilai ekonomi dan sosial ubi jalar merupakan bahan pangan masa depan yang berdaya guna sebagai bahan baku industri dan pakan ternak. Ubi jalar mempunyai potensi yang cukup besar untuk di tingkatkan 
produksinya dan umbinya dapat di proses menjadi aneka ragam produk yang mampu mendorong pengembangan agroindustri dalam divertitikasi pangan. Ubi jalar mempunyai kandungan gizi dan kalori yang sangat penting bagi tubuh yang lengkap di bandingkan pangan pokok lainnya (Harnowo et al.,1994).

Tabel 1. Kandungan Gizi dan Kalori Ubi Jalar, Beras, Ubi Kayu, dan Jagung

\begin{tabular}{cccccccc}
\hline Bahan & $\begin{array}{c}\text { Kalo } \\
\text { ri } \\
(\mathbf{k a l})\end{array}$ & $\begin{array}{c}\text { Karbo } \\
\text { hidrat } \\
(\mathbf{g})\end{array}$ & $\begin{array}{c}\text { Prote } \\
\text { in } \\
(\mathbf{g})\end{array}$ & $\begin{array}{c}\text { Lemak } \\
(\mathbf{g})\end{array}$ & $\begin{array}{c}\text { Vit. } \\
\mathbf{A} \\
(\mathbf{S I})\end{array}$ & $\begin{array}{c}\text { Vit. } \\
\mathbf{C} \\
(\mathbf{m g}\end{array}$ & $\begin{array}{c}\text { Ca } \\
(\mathbf{m g}\end{array}$ \\
\hline Ubi & 123 & 27.9 & 1.2 & 0.7 & 7000 & 22 & 30 \\
jalar & & & & & & & \\
Jalar & & & & & & & \\
Beras & 360 & 78.9 & 6.8 & 0.7 & 0 & 0 & 6 \\
$\begin{array}{c}\text { Ubi } \\
\text { kayu }\end{array}$ & 146 & 34.7 & 1.2 & 0.3 & 0 & 30 & 33 \\
Kayu & & & & & & & \\
Jagung & 361 & 72.4 & 8.7 & 4.5 & 350 & 0 & 9
\end{tabular}

Sumber: Harnowo et al., (1994)
Terdapat banyak kendala yang dihadapi petani sehingga mereka mengalami kesulitan untuk meningkatkan produktivitas dan pendapatannya (kemandirian ekonominya). Pertama, kendala struktural sumber daya lahan. Sebagian besar petani kita adalah petani lahan sempit. Teori ekonomi mengatakan ada ukuran skala ekonomi tertentu dari aktivitas produksi yang harus dipenuhi (economic of scale) agar suatu unit usaha bisa menguntungkan dan efisien. Jelas luas lahan yang sangat rendah tersebut adalah kendala struktural yang dihadapi petani kita untuk memperoleh pendapatan usahatani yang bersifat insentif untuk berproduksi. Kendala kedua adalah masalah rendahnya akses terhadap input pertanian penting. Kendala ketiga adalah minimnya akses terhadap dana dan modal. Sedangkan kendala keempat adalah banyaknya masalah pada pemasaran output yang dihasilkan. (Mubyarto, 1995)

Keuntungan usahatani yang didapat oleh petani merupakan hasil dari penerimaan dikurangi dengan biaya yang telah dikeluarkan selama proses usahatani tersebut berjalan (Hernanto, 2003). Upaya yang dapat dilakukan untuk meningkatkan pendapatan usahatani ubi jalar antara lain dengan cara meningkatkan produksi. Akan tetapi untuk melakukan hal ini petani sering kali terbentur masalah permodalan, karena dengan meningkatkan produksi berarti petani membutuhkan modal awal usaha yang lebih besar. Sementara itu, besar kecilnya penerimaan petani juga bergantung pada jumlah produksi yang dihasilkan dan harga jual ubi jalar tersebut. Sedangkan tingkat harga ubi jalar cenderung selalu rendah dan berfluktuatif, Dalam hal ini petani hanya bertindak sebagai price taker, sehingga posisi tawar petani sangat kecil.

Peningkatan produktivitas dapat di lakukan oleh petani untuk meningkatkan pendapatan. Hal ini dapat dilakukan salah satunya dengan cara pemanfaatan teknik dan teknologi baru yang lebih produktif, antara lain varietas unggul; teknologi budidaya; pengendalian hama dan penyakit; panen dan pascapanen; serta sosial ekonomi dan pemasaran. Upaya tersebut memerlukan sentuhan teknologi yang sesuai dengan kondisi setempat, yaitu secara teknis dapat diterapkan, secara sosial budaya dapat diterima, dan secara ekonomis menguntungkan (Limbongan dan Soplanit). Petani ubi jalar di Desa Panti sebagian besar mengandalkan teknik budidaya yang konvensional. Salah satu upaya yang mungkin dapat dilakukan oleh petani adalah dengan penghematan biaya usahatani, agar penerimaan aktual yang diterima petani dapat lebih tinggi. Pengeluaran yang paling bisa dihemat adalah biaya-biaya yang bersifat biaya variable yaitu biaya yang diantaranya adalah bibit, pupuk, obat-obatan (pestisida), tenaga kerja, dll. Sistem pertanian konvensional yang merupakan sistem pertanian dengan menggunakan bahanbahan kimia seperti pupuk kimia, pestisida kimia serta obat- obatan kimia lain memang terbukti mampu meningkatkan produktivitas tanah dalam waktu yang relatif pendek. Namun tidak dapat dipungkiri bahwa akibat perlakuan proses produksi tersebut, dalam jangka panjang akan mulai tampak tandatanda terjadinya kelelahan pada tanah dan penurunan produktivitas pada hamper semua jenis tanaman yang diusahakan. Apabila tidak ada tindakan lebih lanjut untuk memperbaikinya, maka akan menimbulkan dampak buruk lanjutan terhadap kelestarian dan kesehatan lingkungan disekitarnya.

Konsep pertanian berbasis organik merupakan salah satu teknologi budidaya yang memungkin adanya upaya penghematan biaya bagi usahatani ubi jalar. Selain petani dapat menghemat biaya, petani juga ikut berpartisipasi dalam upaya penyediaan pangan yang sehat. Hal ini juga sejalan dengan perspektif pertanian di masa yang akan datang. Konsep organik yang dimaksud dapat dilakukan dengan cara tidak menggunakan pupuk kimia dan obat-obatan atau pestisida dalam budidaya ubi jalar yang dilakukan (Limbongan dan Soplanit, 2007) .

Seanjutnya upaya usahatani ubi jalar secara organik maka petani dapat 
mengurangi beberapa struktur biaya sehingga hal ini diharapkan dapat meningkatkan keuntungan bagi petani ubi jalar

\section{METODE PENELITIAN}

Pemilihan lokasi penelitian ini ditentukan secara sengaja (purposive) dengan pertimbangan bahwa Desa Panti Kecamatan Panti Kabupaten Jember merupakan salah satu sentra produksi dan pengembangan ubi jalar di Kabupaten Jember. Pelaksanaan penelitian telah dilakukan selama dua bulan, dari bulan April sampai bulan Mei 2018.

Metode yang digunakan dalam penelitian ini adalah deskriptif, yaitu suatu metode penelitian yang dilaksanakan untuk meneliti status kelompok manusia ataupun suatu peristiwa yang terjadi pada saat sekarang. Tujuan dari penelitian deskriptif adalah untuk membuat deskripsi secara sistematis, factual, akurat mengenai fakta-fakta, sifat-sifat serta hubungan antara fenomena-fenomena yang diselidiki (Nazir, 1988). Menurut pendapatat Soekartawi (1995) bahwa untuk mengetahui pendapatan usahatani ubi jalar digunakan rumus sebagai berikut :

$$
\begin{aligned}
& \pi=\text { TR }- \text { TC } \\
& \text { TR = P } \times \text { Q } \\
& \text { TC }=\text { TFC + TVC }
\end{aligned}
$$

Keterangan:

$\pi=$ Pendapatan $(\mathrm{Rp})$

$\mathrm{P}=$ Harga Produksi Ubi Jalar $(\mathrm{Rp} / \mathrm{Kg})$

$\mathrm{Q}=$ Jumlah produksi Ubi Jalar $(\mathrm{Kg})$

$\mathrm{TR}=$ Total penerimaan $(\mathrm{Rp})$

$\mathrm{TC}=$ Total biaya usahatani Ubi Jalar (Rp)

$\mathrm{TFC}=$ Total biaya tetap $(\mathrm{Rp})$

$\mathrm{TVC}=$ Total biaya variabel $(\mathrm{Rp})$

Guna mengetahui efisiensi usahatani ubi jalar digunakan Revenue Cost Ratio (R/C) yang secara matematis dapat dituliskan sebagai berikut (Hernanto, 2003):

\section{$\mathrm{R} / \mathrm{C}$ Ratio $=\mathbf{T R}$}

$$
\overline{\text { TC }}
$$

Dengan kriteria :

$\mathrm{R} / \mathrm{C}>1$, berarti usahatani ubi jalar efisien atau menguntungkan

$\mathrm{R} / \mathrm{C}<1$, berarti usahatani ubi jalar tidak efisien atau tidak menguntungkan

$\mathrm{R} / \mathrm{C}=0$, berarti usahatani ubi jalar mengalami titik impas

\section{HASIL DAN PEMBAHASAN}

Pendapatan usahatani adalah selisih antara penerimaan usahatani dengan biaya produksi. Analisis pendapatan usahatani merupakan alat untuk mengetahui keberhasilan suatu kegiatan usahatani. Suatu usahatani dapat menguntungkan jika pendapatan usahatani tersebut bernilai positif dan merugikan jika pendapatan usahatani tersebut bernilai negatif. Dalam penelitian ini biaya bibit dimasukkan karena adanya beberapa petani responden yang melakukan pembelian bibit untuk usahatani ubijalarnya dari petani lain. Untuk memudahkan dalam menyeragamkan perhitungan biaya bibit, maka pada petani responden yang melakukan pembibitan sendiri atau mengambil bibit dari musim tanam sebelumnya dilakukan perhitungan tenaga kerja dalam pembuatannya dan dimasukkan ke dalam biaya bibit secara tunai, hal ini dilakukan dengan pertimbangan bahwa petani responden secara langsung mengeluarkan biaya tunai untuk bibit tersebut.

Analisis pendapatan usahatani meliputi analisis penerimaan, analisis biaya, analisis pendapatan serta analisis $\mathrm{R} / \mathrm{C}$ rasio usahatani ubi jalar. Analisis pendapatan usahatani membutuhan dua data pokok yaitu data penerimaan dan data pengeluaran selama periode waktu yang telah ditetapkan. Oleh karena itu untuk dapat mengetahui besarnya pendapatan yang diterima harus diketahui terlebih dahulu data penerimaannya dan biaya, untuk mendapatkan data penerimaan dilakukan analisis terhadap penerimaan responden per hektar. Sedangkan untuk mendapatkan data biaya yang dikeluarkan dilakukan analisis biaya.

Pada kondisi di lapangan data yang diperoleh sangat bervariasi, sehingga untuk memudahkan proses penghitungan semua data penerimaan dan biaya dikonversi agar data yang diperoleh menjadi seragam dan bisa diperbandingkan. Setelah data dikonversi, maka analisis pendapatan usahatani ubi jalar yang dilakukan pada penelitian ini adalah analisis pendapatan usahatani ubi jalar yang dilakukan pada lahan seluas satu hektar dan dalam jangka waktu satu musim tanam.

Pendapatan usahatani ubi jalar merupakan selisih antara total penerimaan usahatani dengan total pengeluaran usahatani. Dapat dilihat pada Tabel 2 bahwa penerimaan rata-rata usahatani ubi jalar dalam satu musim tanam Rp 63.444.198,78 dengan biaya-biaya yang dikeluarkan sebesar Rp 22.052.029,49 maka di didapatkan keuntungan usahatani sebesar Rp 41.392.169,29. Hal ini menunjukkan bahwa petani di Desa Panti sudah mampu bekerja usahatani dengan baik dan harus mampu di kembangkan. Dengan pendapatan usahatani sebesar Rp 41.392.169,29 per satu musim tanam atau 4-6 bulannya jadi selama perbulan dalam usahatani ubi jalar didapat sebesar Rp 8.278.433,86. Hal ini menunjukkan bahwa pendapatan usahatani ubi jalar di lokasi 
penelitian cukup tinggi bila di bandingkan dengan UMR wilayah Jember sebesar Rp 1.700 .000 .

Tabel 2. Analisis Pendapatan Usahatani Ubi Jalar Petani Responden

\begin{tabular}{|c|r|r|}
\hline Uraian & (Rp) & \multicolumn{1}{c|}{ (Rp) } \\
\hline Penerimaan usahatani ubi jalar & & $\mathbf{6 3 . 4 4 4 . 1 9 8 , 7 8}$ \\
\hline Biaya - biaya & & \\
\hline Pajak Lahan & $88.552,5$ & \\
\hline Bibit & $953,210.71$ & \\
\hline Tenaga Kerja & $13.598 .818,78$ & \\
\hline Biaya Sewa Lahan (1 musim) & 7.500 .000 & \\
\hline Total Biaya Usahatani & $\mathbf{2 2 . 0 5 2 . 0 2 9 , 4 9}$ & \\
\hline Pendapatan Usahatani & & $\mathbf{4 1 . 3 9 2 , 1 6 9 . 2 9}$ \\
\hline
\end{tabular}

Sumber : Data Primer Diolah, 2018

Berdasaran Tabel 2 di atas juga dianalisis bahwa pendapatan usahatani ubi jalar di lokasi penelitian sudah efisien. Artinya kegiatan usahatani ubi jalar memiliki tingkat efisiensi penggunaan biaya yang tergolong tinggi. Kondisi ini ditandai dengan nilai R/C yang cukup tinggi yaitu 2,88. Angka tersebut memiliki interpretasi bahwa setiap $\mathrm{Rp} 1$ biaya yang dikeluarkan oleh petani, maka akan memperoleh penerimaan sebesar $\mathrm{Rp} 2,88$ atau keuntungan sebesar Rp 1,88. Hasil penelitian ini didukung oleh hasil penelitian Asmarntaka dan Zainuddin (2017) yang mengungkapkan bahwa usaha tani ubi jalar Desa Petir telah efisien secara teknis dengan nilai rata-rata sebesar 0,95.

\section{KESIMPULAN}

Rata-rata total biaya usahatani ubi jalar di lokasi penelitian sebesar Rp 22.052.098,49 per hektar dan rata-rata penerimaan mencpai $\mathrm{Rp}$ 63.444.198,78 per hektar, sehingga pendapatan usahatani ubi jalar tersebut sebesar Rp 41.392.169,29 per hektar. Berdasarkan kondisi di atas maka kegiatan usahatani ubi jalar petani di lokasi penelitian berjalan efisien yang ditandai dengan nilai R/C sebesar 2,88.

\section{DAFTAR PUSTAKA}

Akhmad, 2016. Budidaya Ubi Jalar dan Permasalahan Yang Petani Hadapi. https://www.akhmadshare.com/petanibudidaya-ubi-jalar.html. Didownload pada tanggal 05 Januari 2018.

Asmarantaka, R.W. dan Zainuddin, 2017. Efisiensi dan Prospektif Usaha Tani Ubi Jalar (Studi Kasus Desa Petir, Dramaga, Jawa Barat, Indonesia). Jurnal PANGAN. Vol. 26 (01). Hal: $23-36$.

Harnowo, D., S.S. Antarlina, dan H. Mahagyosuko. 1994. Pengolahan Ubi Jalar Guna Mendukung Diversifikasi Pangan dan Agroindustri. Risalah Seminar Penerapan Teknologi Produksi dan Pascapanen Ubi Jalar Mendukung Agroindustri. Balittan Malang: 123-129.

Hernanto, F. 2003. Ilmu Usaha Tani. Jakarta: Penerbit Swadaya.

Limbongan, J. dan Soplanit, A. 2007. Ketersediaan teknologi dan potensi pengembangan ubi jalar. di Papua. Jurnal Litbang. Penelitian 26(4). Balai Pengkajian Teknologi Pertanian, Papua

Mariyam, Yuliarti, Hidayati, S., 2009.

Deversifikasi Konsumsi Pangan Masyarakat Kota Yogyakarta. Prosiding Seminar Nasional Penelitian, Pendidikan dan Penerapan MIPA, Fakultas MIPA, Universitas Negeri Yogyakarta. Hal: 158 - 165. http://eprints.uny.ac.id. Diunduh pada tanggal 05 Januari 2018.

Mubyarto. 1995. Pengantar Ekonomi Pertanian. Jakarta: LP3ES.

Nazir M., 1988, Metode Penelitian, Cetakan ke3. Jakarta: Ghalia Indonesia.

Soekartawi. 1995. Analisis Usahatani. Jakarta: Universitas Indonesia (UI) Press. 